\title{
Probabilistic Multiple Pedestrian Walking Force Model including Pedestrian Inter- and Intrasubject Variabilities
}

\author{
Zandy O. Muhammad (iD) and Paul Reynolds \\ Vibration Engineering Section, College of Engineering, Mathematics and Physical Sciences, University of Exeter, Exeter, UK \\ Correspondence should be addressed to Zandy O. Muhammad; zm247@exeter.ac.uk
}

Received 22 July 2019; Accepted 18 December 2019; Published 10 January 2020

Academic Editor: Harry Far

Copyright (C) 2020 Zandy O. Muhammad and Paul Reynolds. This is an open access article distributed under the Creative Commons Attribution License, which permits unrestricted use, distribution, and reproduction in any medium, provided the original work is properly cited.

\begin{abstract}
A probabilistic walking load model that accounts for inter- and intrasubject variabilities has been developed to generate synthetic vertical load waveforms induced by pedestrians. The mathematical model is based on a comprehensive database of continuously recorded pedestrian walking forces on an instrumented treadmill, having a wide range of walking frequencies. The proposed model is able to replicate temporal and spectral features of real walking forces, which is a significant advantage over conventional Fourier series models. The load model results in more realistic force time histories than previous models, since it incorporates significant components of the spectra that are omitted in Fourier series approaches. The proposed mathematical model can be implemented in vibration serviceability assessment of civil engineering structures, such as building floors and footbridges, to estimate more realistically dynamic structural responses due to people walking.
\end{abstract}

\section{Introduction}

Contemporary civil engineering structures, such as slender floors, footbridges, manufacturing facilities, and operating theatres, occupied and dynamically excited by human footfall loading, require the critical design aspect of vibration serviceability to be evaluated via prediction of vibration responses and subsequent performance assessment. In the particular case of floors, present and contemporary guidance methodologies [1-4] are often followed to assess vibration serviceability. However, even if properly applied, the outcome may be unsatisfactory, leading to a knock-on effect on building or facility owners and thus litigation [5]. The key reasons for this are (1) the lack of adequate and accurate design procedures in contemporary design guidelines [6], (2) a lack of appreciation of the importance of vibration serviceability design dominance relative to other design parameters, such as strength and deflections, (3) the lack of a probabilistic modelling strategy to account for variability of excitation source and hence representative footfall loading model [7], and (4) the lack of appropriate assessment criteria for subjective human perception $[6,8]$. These, by nature, lead to a major challenge in modern floor design, whereby the prediction of vibration responses under human-induced footfall remains demanding and uncertain [9].

Vibration analyses of floors, in design guidance documents [1-3], are commonly addressed based on a frequency threshold of first mode natural frequency. This threshold, accepted as around $10 \mathrm{~Hz}$, results in two classes of floors, low-frequency floors (LFF) if below the threshold and highfrequency floors (HFF) if above the threshold, irrespective of the function and usage of the floor. Forced vibrations for LFF are assumed to be deterministic, even though CSTR43 App $\mathrm{G}$ and CCIP-016 introduce the concept of $25 \%$ probability of exceedance on DLFs. As such, the floor develops a resonant response by harmonic components of the force, whereas HFFs are assumed to undergo transient response under impulsive footfall loading. However, these studies $[5,6,10]$ have shown that design guidelines do not work in many cases and require major improvements in all aspects, particularly in walking load models and design scenarios. This is owing to the fact that all the models assume walking as 
deterministic. The walking force is, however, not deterministic due to random variabilities inherent in real walking.

There have been a number of attempts to develop reliable synthetic walking load models by a single pedestrian for vibration serviceability assessment, such as a stochastic load model using a number of Gaussian curves by [11]. This model relies on random parameters being drawn from an experimental database, resulting in a detailed representation of a continuous walking force. However, access to the experimental database is a prerequisite to implement the above model, which is not available to the public domain. Živanović [12] proposed a probabilistic walking model for footbridges considering a single pedestrian. The forcing function was represented by a Fourier series and the parameters were modelled using statistical values for the first five main harmonics based on the data of Kerr [13] and Brownjohn et al. [14]. However, it is reported that the Fourier approach results in loss of information and introduction of inaccuracies for individual and multiple pedestrians [11]. All of these walking load models tend to generate a continuous force time history rather than individual steps from both footfalls. A walking model based on individual footfalls might better describe the mechanism of walking and its parameters. Therefore, the aforementioned load models do not tend to reflect the true nature of pedestrian excitation, which has potential for the variation in pacing frequency at the same velocity or walking speed. A potential load model can be established on the basis of right and left or strong and weak legs, which could serve both single and multiple pedestrian loading scenarios. This in turn can be used as a unified load model for a wider frequency range. This could be achieved via a probabilistic framework that accounts for the inter- and intrasubject variability in the walking force modelling as well as the potential excitation at different walking speed.

The model developed in this paper advocates using a statistical approach for generating time domain walking forces from individual steps (right and left footfalls) for individual and multiple pedestrians based on pedestrian walking speed. The established model can be reproduced from the data and equations illustrated in the following sections. In addition, the model can be used in discrete footfall analysis when individual steps are applied on different structural components. It can be implemented in any finite element (FE) package for vibration serviceability analysis. This can facilitate the application of individual walking step forces at sequential spatial positions along any walking paths. The frequency domain components of the model have features of measured walking in exhibiting the narrow band random process, which is vital for reliable vibration serviceability assessment. The model is developed based on a large database of continuously recorded walking forces on an instrumented treadmill for significant numbers of individuals. The measured database, to the authors' best knowledge, is the most comprehensive collection of continuous walking forces available in the literature. The modelling strategy is followed by extracting key points on the shape of measured footfalls to develop statistical relationships for right and left steps of an individual. Following the introduction, Section 2 presents the measured database and Section 3 introduces key statistical parameters of individual walking steps and their relationships. In Sections 4 and 5, the continuous probabilistic walking force and its validation are illustrated. Section 6 summarises overall probabilistic model strategy based on left and right footfalls and discusses its limitations.

\section{Continuous Measurement of Walking Data on Instrumented Treadmill}

Developing a realistic walking load model requires a wide range of continuously measured actual walking forces for different pedestrians, so as to retain the essence of the inherent variabilities of real walking. The measured database used in this paper has previously been discussed and utilised by [11], but some key points are mentioned in this section.

Right and left footfalls of each person were continuously and independently recorded on an instrumented split-belt treadmill sampled at $200 \mathrm{~Hz}$. The acquisition of walking records was not prompted by any stimuli such as a metronome but instead was controlled by the treadmill speed (i.e., constant treadmill speed), which started from $0.56 \mathrm{~m} / \mathrm{s}$ and increased in increments of $0.14 \mathrm{~m} / \mathrm{s}$ up to the maximum comfortable walking speed. This is an inherent limitation of force measurement using instrumented treadmills. Walking forces corresponding to ten different walking speeds were collected for each person. Each person has different maximum speed due to their overall height and leg length. Each test was completed when at least 64 successive footfalls were acquired. In total, 852 vertical time histories of walking forces were collected for 85 people. Their characteristic mean and standard deviation of body mass, height, and age are $75.8 \pm 15.2 \mathrm{~kg}, 174.4 \pm 8.2 \mathrm{~cm}$, and $29.8 \pm 9.1$ years, respectively. The reader is referred to $[5,11]$ for more details. In this paper, only 600 time histories of walking forces were used to develop the load model, for walking below $0.8 \mathrm{~m} / \mathrm{s}$ and walking above $2.2 \mathrm{~m} / \mathrm{s}$ have low probability [15]. A typical measured walking force time history is illustrated in Figure 1.

\section{Modelling Strategy of Individual Walking Steps}

This section presents the concept of the modelling approach for each footfall from analysis of the continuous measured walking. Right and left footfalls are considered separately to extract time and load components based on a single step. Establishment of these two components is based on the aforementioned measured data generated by a diverse range of pedestrians, which will provide statistical reliability in the consideration of both inter- and intrasubject variabilities.

\subsection{Key Parameters for the Walking Step}

3.1.1. Walking Speed. Walking speed has a large effect on temporal and spatial parameters of walking and hence is considered a significant parameter in this model for a number of reasons. Firstly, numerous studies have 


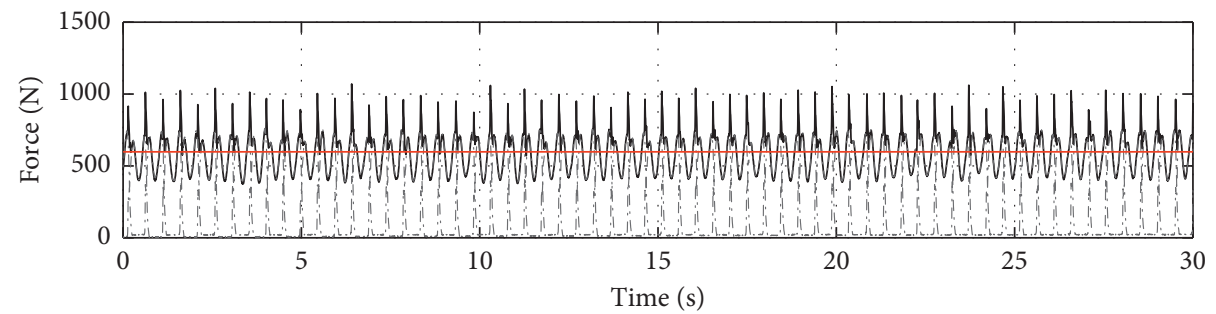

- Total force

.... Right and left footfall

— Weight

(a)

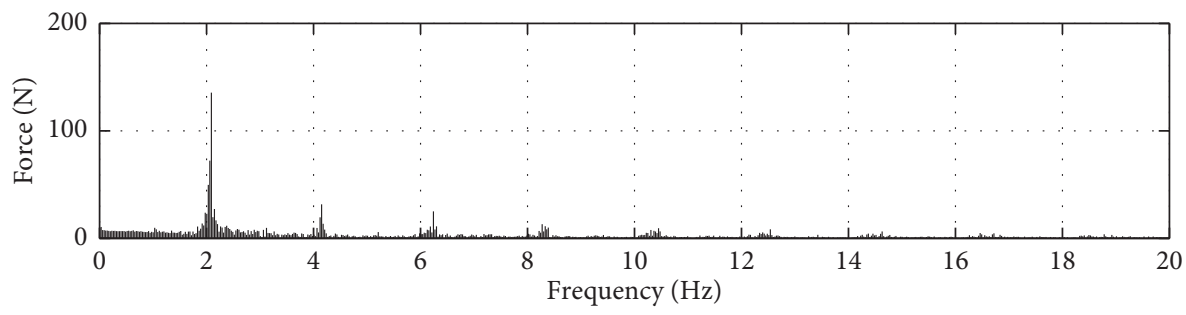

(b)

Figure 1: Walking force time history and Fourier spectrum at a speed of $1.341 \mathrm{~m} / \mathrm{s}$.

characterised relationships between walking speed and stride-length, step-length, step-width, and pacing frequency $[16,17]$. Secondly, pedestrians naturally walk at different velocities that in an effortless way increase or decrease pacing frequency and spatial parameters [17]. Thirdly, individuals walking at the same speed have different excitation dynamic forces as well as different walking parameters, which could be hard to account for individually in any forcing function. Therefore, walking speed tends to be a global parameter that is inherently capable of defining distributions of several walking (temporal-spatial) parameters, which are vital in producing walking forces. The walking load model in this paper considers walking speed as the input parameter due to the aforementioned observations, unlike any existing walking models. In this study, the range of walking speed is between $0.8 \mathrm{~m} / \mathrm{s}$ for slow walking and $2.2 \mathrm{~m} / \mathrm{s}$ for fast walking. These values, based on the observations in [16], correspond to the pacing frequency of $1.4 \pm 0.1 \mathrm{~Hz}$ and $2.3 \pm 0.1 \mathrm{~Hz}$, respectively.

3.1.2. Step Contact Time. Step contact time or stance time is the time when a foot is in contact with the ground. The step contact time itself depends on walking speed, as presented in the next section. This will later be used in deriving relations of control points on a step. Figure 2 shows the shape of the force of a single walking step, where there are five main control points: The start point, which has zero load and time. The first peak load, which is the first local peak amplitude of the force. The second peak load, which is the second local peak amplitude of the force on the shape of a walking step. First peak point is initiated with heel strike (heel contact) and second peak point is where the toe of the same foot hits the ground. This phase is called stance phase or contact

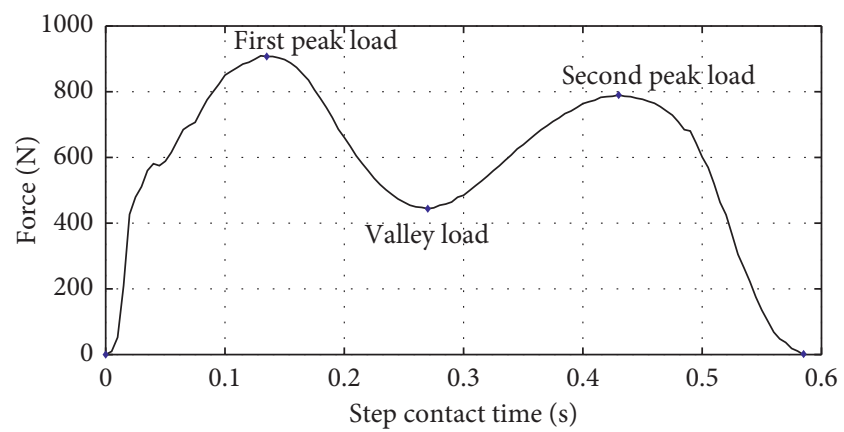

Figure 2: Shape of a typical measured walking step with time and load components.

phase. The valley load, which is the trough or a low point on the shape of a walking step between first peak and second peak. Also, the step contact time, which is the last point. Any points in between these main points are called intermediate points. The intermediate points are those points that lie between first peak point and valley point or valley point and second peak point, which will be discussed later. The right and left footfall shapes are represented in the following sections using a set of intermediate and control points, which have different values, probabilistically generated using mean and standard deviation, for each footfall of walking.

3.1.3. Overlap Time between Two Consecutive Steps. Overlap time or double support time is the period of time when both feet are in contact with the ground simultaneously. This period of time becomes proportionally shorter as the walking speed increases, and when it becomes zero it indicates the transition to running. The overlap time 
depends on both walking speed and step contact time, based on the analysis of the measured data discussed later.

3.2. Timing Component of a Step. This section provides a statistical description of the timing components of the control points on the shape of a walking step. The relations are derived between walking speed and step contact time as well as the points described in Figure 2. Statistical relationships among pedestrians were also formulated to account for inter- and intrasubject variabilities in the form of probability distribution functions.

3.2.1. Step Contact Time Relationship. There is a linear relationship between the walking speed and step contact time (in seconds) based on the aforementioned measured data, as shown in Figure 3. Each measured data point corresponds to an individual at that particular walking speed. It can be seen that the step contact time decreases with an increase in the walking speed. The measured data were extracted for each person's footfall for the duration of measured walking using gradient point (i.e., slope at that point) in MATLAB. The gradient of a line is a number that describes both the direction and the steepness of the line between two points. A margin of error equal to $2 \mathrm{~d} t$, where $\mathrm{d} t=0.005 \mathrm{~s}$, was introduced in the gradient point to achieve the lowest (ideally zero) slope due to the effect of noisiness in the data, thus obtaining a better estimate of beginning and ending of a step. Both the beginning and ending of a footfall were obtained separately and the subtraction of them gives an estimate of the step contact time (in seconds). The measured data shown in Figure 3 are the mean values for each person for both footfalls (i.e., left and right footfalls). The theoretical mean is the best fit with a high value of $R^{2}$, which indicates the goodness of fit or degree of linear correlation of the model.

Subject variabilities can be observed from the measured data and as such this study takes into account both inter- and intrasubject variabilities. Intersubject variations, which exist between pedestrians, are represented by a normal distribution through mean $(\mu)$ and standard deviation $(\sigma)$. The $\mu_{\text {inter-subject contact }}$ (in seconds) is obtained by the theoretical mean of Figure 3, whereas $\sigma_{\text {inter-subject contact }}$ is computed for each walking speed using both $\mu$ and $\sigma$. Since these two values are different, coefficient of variation $(\mathrm{CoV})$ was calculated, which is $\mu$ divided by $\sigma$. Averaging the $\mathrm{CoV}$ and relating that to the mean will give the standard deviation. Thus, $\sigma_{\text {inter-subjectcontact }}$ is, among individuals, an average value of $6.61 \%$ of $\mu_{\text {inter-subject contact }}$ (in seconds). As far as intrasubject variations are concerned, which occur within the same pedestrian, $\mu$ and $s$ are calculated for each person based on measured data, having $\mu_{\text {intra-subject contact }}$ of $0.0 \mathrm{~s}$ and $\sigma_{\text {intra-subject contact }}$ of $0.0138 \mathrm{~s}$.

3.2.2. First Peak Time, Valley Time, and Second Peak Time. First peak time, valley time, and second peak time of right and left footfalls (in seconds) are calculated as a function of step contact time as illustrated in Figures 4-6. Using step contact time for all timing components is utilised due to the

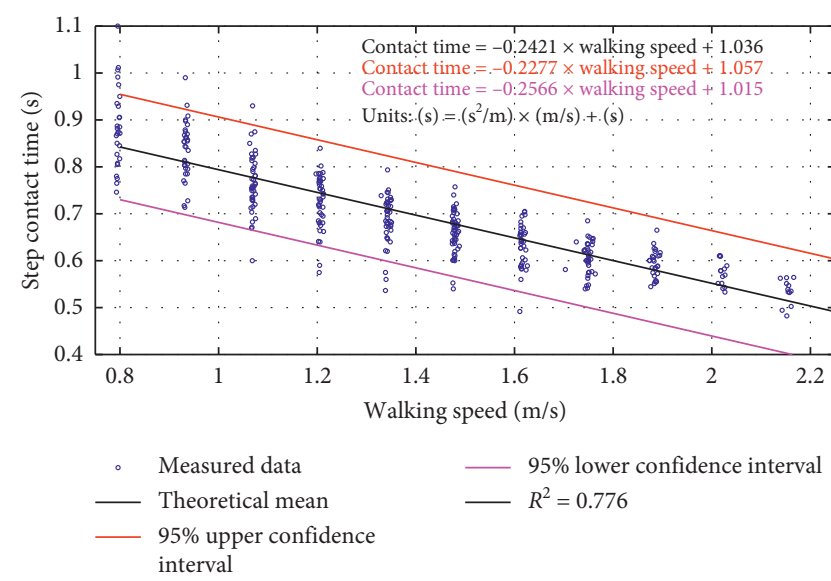

FIGURE 3: Statistical relationship between walking speed and step contact time.

fact that first peak time, valley time, and second peak time (in seconds) are all proportions of a step contact time (in seconds). The reason for both footfalls is to preserve the intrasubject variabilities that are innate in actual walking and as such each footfall has its own formula. With an increase in the step contact time, the timing components increases, which is due to the slow walking. These timings are the key control points in defining the intermediate points in between them.

3.3. Loading Component of a Step. The relationship between walking speed and loading components of a step can be observed from the measured data. Figure 7 shows that first peak load, normalised by body weight (NBW), is dependent on walking speed. Statistical relationships among pedestrians were also formulated to account for subject variabilities in the form of probability distribution functions, which are assumed to follow normal distributions based on measurement observations. Therefore, $\mu_{\text {inter-subject 1st peak }}$ is given by the theoretical mean of Figure 7 for right and left footfalls, whereas $\sigma_{\text {inter-subject 1st peak }}$ is computed with average values of 0.0772 and 0.06464 for right and left footfalls, respectively. As far as intrasubject variations are concerned, $\mu$ and $s$ are calculated, based on measurement, for right and left footfalls as $\mu_{\text {intra-subject 1st peak }}$ of 0.02929 and 0.0339 and $\sigma_{\text {intra-subjective 1st peak }}$ of 0.0218 and 0.01596 , respectively.

Similar relationships can be developed for the valley load (NBW), as shown in Figure 8. Normal distribution was assumed to govern the inter- and intrasubject variabilities, which was also in line with the measurement observation. Therefore, $\mu_{\text {inter-subject valley }}$ is given by the theoretical mean of Figure 8 for right and left footfalls, whereas $\sigma_{\text {inter-subject valley }}$ is computed with an average value of 0.0505 and 0.0484 for right and left footfalls, respectively. As far as intrasubject variations are concerned, $\mu$ and $s$ are calculated for right and

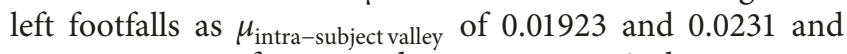
$\sigma_{\text {intra-subject valley }}$ of 0.013 and 0.0104 , respectively.

As far as second peak load (NBW) is concerned, the relationship is such that the second peak load depends on both walking speed and first peak load as shown in Figure 9. 


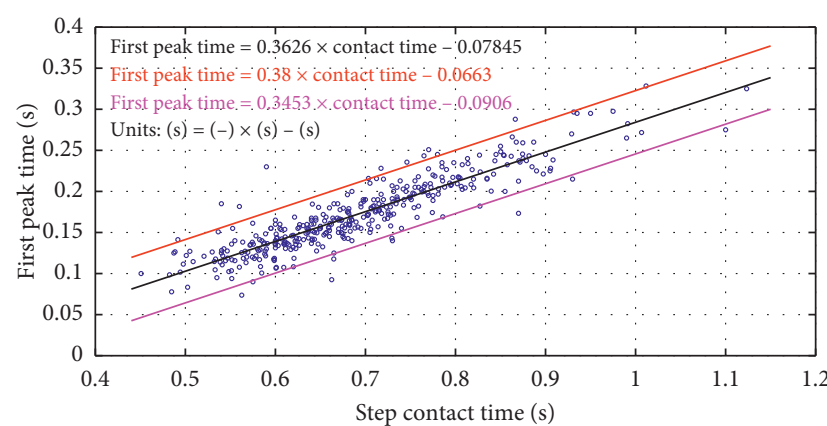

- Measured data

_ Theoretical mean

- $95 \%$ upper confidence interval

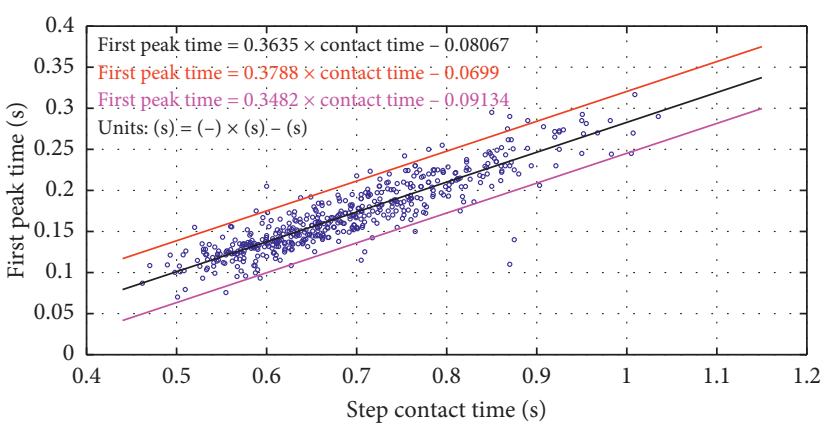

- Measured data _ _ $95 \%$ lower confidence interval

- Theoretical mean

- $95 \%$ upper confidence interval

(a)

(b)

FIgURE 4: Statistical relationship between step contact time and first peak time. (a) Right footfall; (b) left footfall.

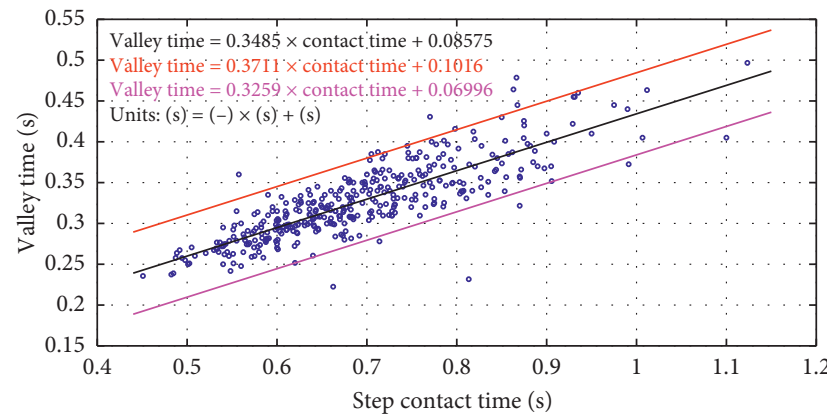

- Measured data

- Theoretical mean

- $95 \%$ upper confidence interval

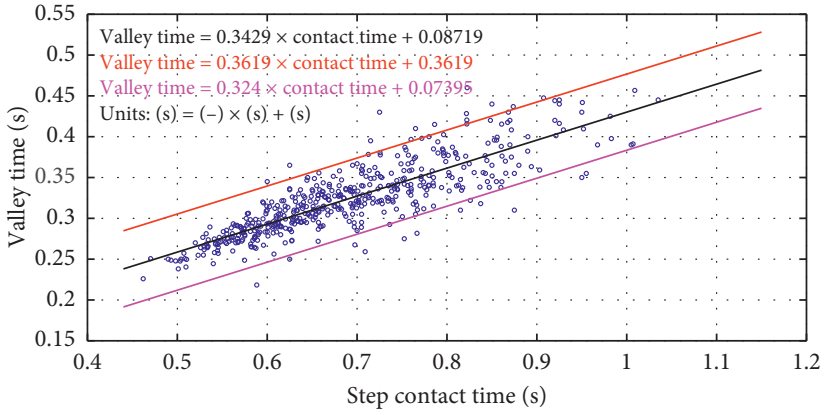

- Measured data

- Theoretical mean

- $95 \%$ upper confidence interval

(a)

(b)

Figure 5: Statistical relationship between step contact time and valley time. (a) Right footfall; (b) left footfall.
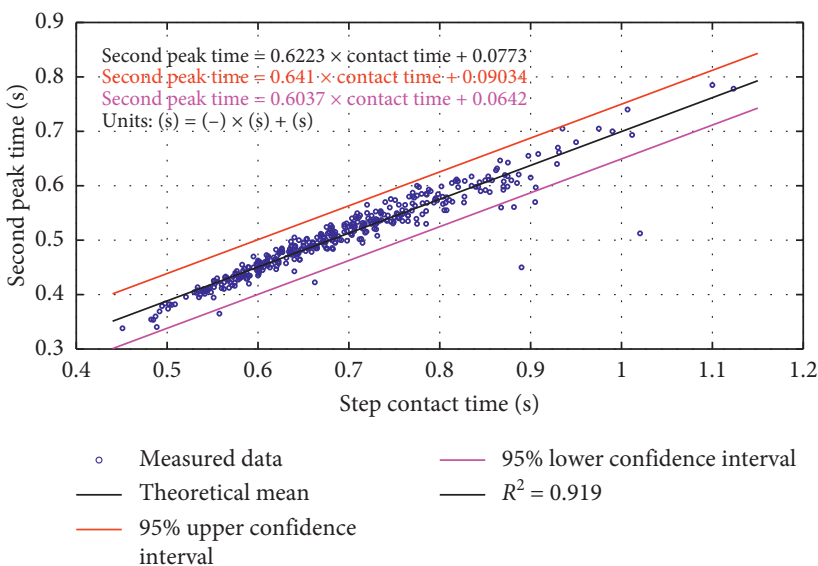

(a)

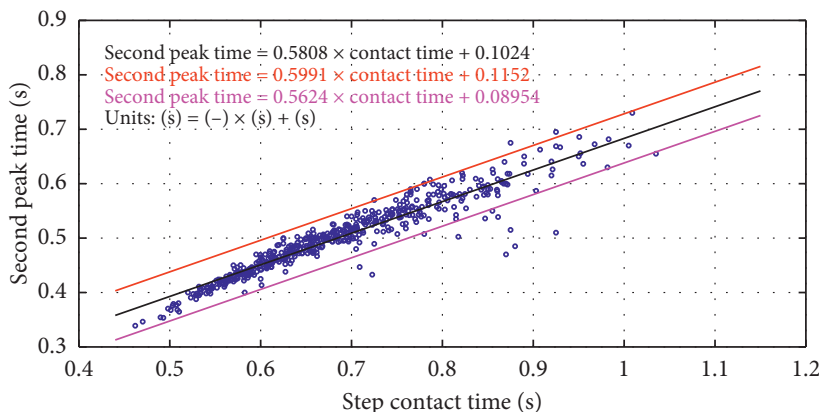

Measured data
Theoretical mean
95\% upper confidence

- 95\% lower confidence interval

$-R^{2}=0.886$

(b)

Figure 6: Statistical relationship between step contact time and second peak time. (a) Right footfall; (b) left footfall. 


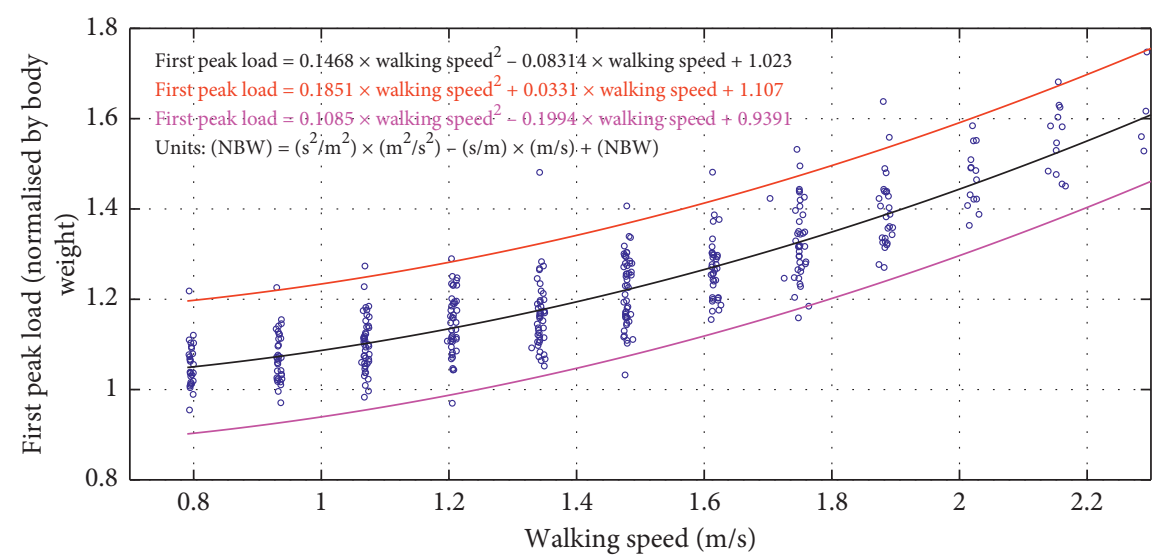
- Measured data
- Theoretical mean
_ $95 \%$ lower confidence interval
_ $95 \%$ upper confidence interval
- $R^{2}=0.802$

(a)

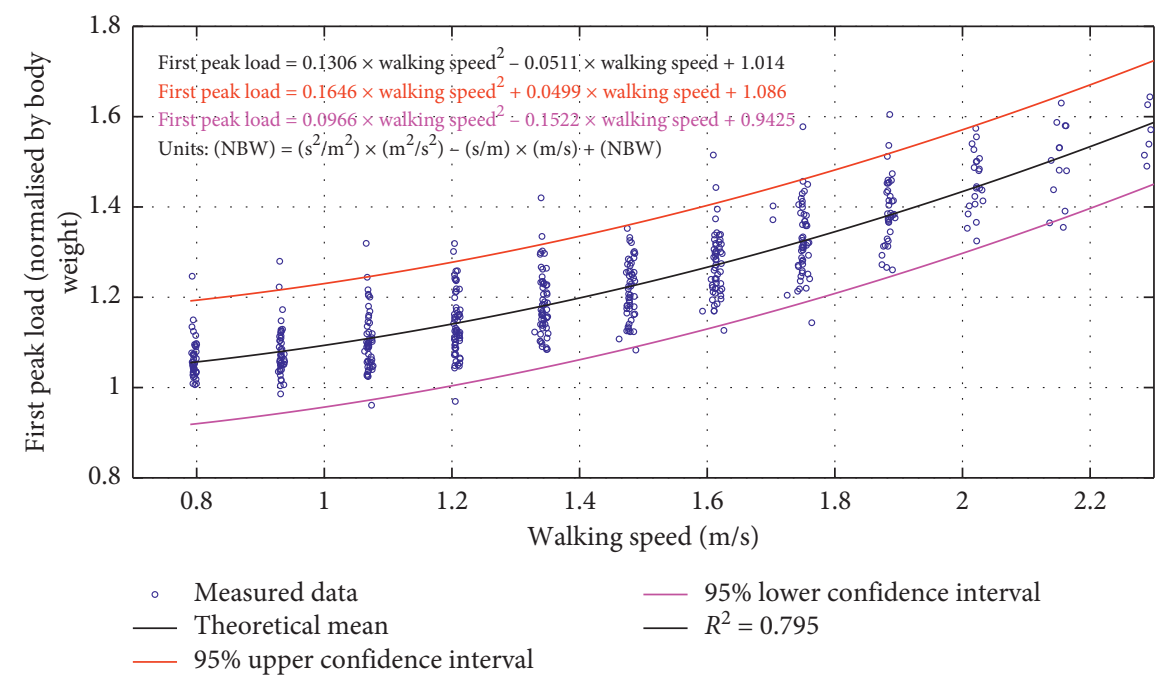

(b)

FIgURE 7: Statistical relationship between walking speed and first peak load. (a) Right footfall; (b) left footfall.
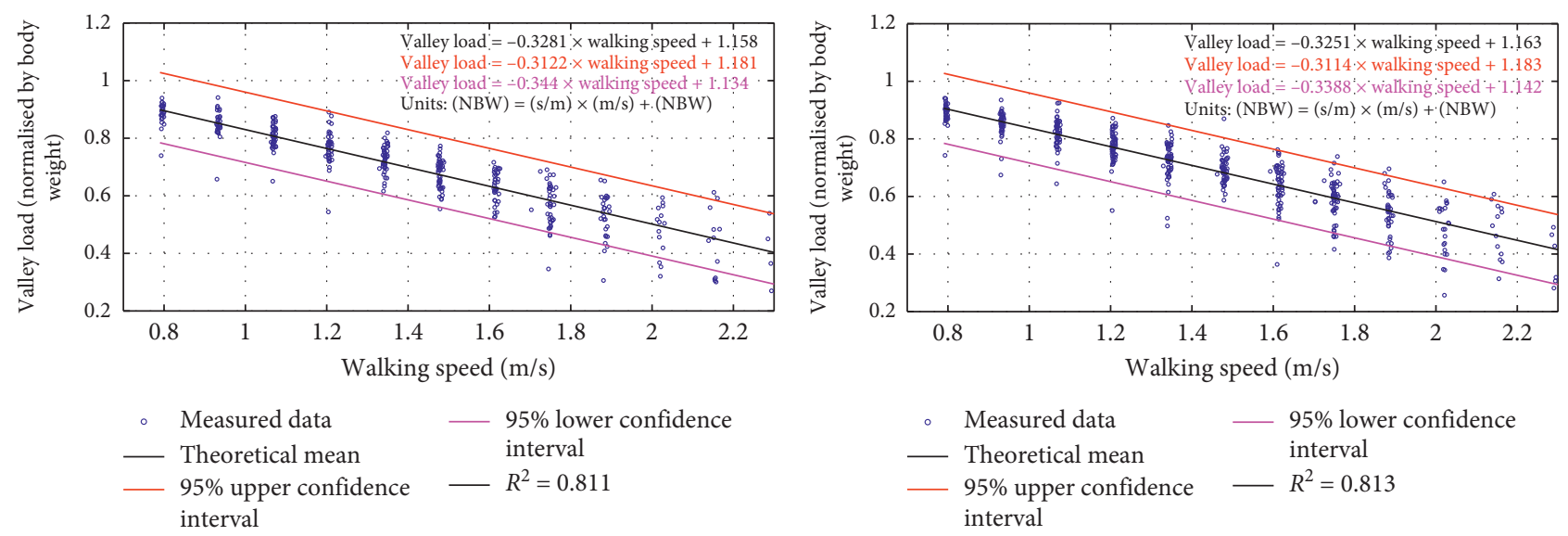

(a)

(b)

FIGURE 8: Statistical relationship between walking speed and valley load. (a) Right footfall; (b) left footfall. 
This is due to the goodness of fit, where poor relationships would result if the second peak load was derived only based on walking speed (this is not shown here for clarity). The intersubject variabilities have already been taken into account because of dependence on the first peak load. The intrasubject variabilities, on the other hand, follow a normal distribution with $\mu$ and $s$ calculated for right and left footfalls as $\mu_{\text {intra-subject 2nd peak }}$ of 0.0352 and 0.0368 and $\sigma_{\text {intra-subject 2nd peak }}$ of 0.01895 and 0.01862 , respectively. It is worth pointing out that this model assumes independent probability distribution of individual parameters featuring in the model and human-structure interaction (HSI) is not included.

3.4. Model Development Methodology. The control points established in the aforementioned sections are critical in defining the rest of the points. The intermediate points' relationships are mainly dependent on the above main control points. For example, points between beginning of a step and first peak point were estimated based on the proportion of the first peak load and/or first peak time. These criteria were set after a significant number of trials (by the authors) when visually checking the walking measurements. For instance, second point (P2) is at $1 \%$ of first peak load and $1 / 7.5$ of first peak time. Third point (P3) is at $1.2 \%$ of first peak load and 1/5.1 of first peak time. Satisfying both of these conditions was selected to extract the points. Similarly, for all the other points, different conditions were set to extract the rest of the points. This was done to capture the changes on the beginning of the step as the force value increases. For points between first peak and valley point, the conditions were as follows: point fifteen (P15) is at a fraction (1/1.2) of time between the difference of first peak and valley point. The same methodology was followed for points between valley and second point as well as second point and end of a step. Following extraction of these points, regression analysis [18] was used to develop the statistical relationships. A number of the relationships for the points had very small $R^{2}$ (i.e., weak relationship); thus those with $R^{2}<0.5$ were improved by relating to points with a better $R^{2}$. The relationships are shown in Table 1, where time components are in seconds and load components are normalised by body weight (NBW). These intermediate points, which are 34 points including the control points, tend to match the shape of an actual walking step. Although more points could have been chosen, this may have led to a tedious process and become less effective. Therefore, spline interpolation in MATLAB is utilised to generate smooth walking steps for the above points as shown in Figure 10.

A number of regenerated walking footfall time history for both right and left footfalls can be seen in Figure 10 in terms of mean and individual steps, which matches the corresponding measured walking step closely. Since actual walking is a continuous process, continuity of walking is established via the overlap time between consecutive right and left footfalls. This was done by placing any consecutive step at a specific time slot, which is computed from previous step contact time subtracted from an overlap time. The overlap time is a function of both walking speed and step contact time as shown in Figure 11. The theoretical mean value only will be used to construct a continuous walking load time history, since the overlap time depends partly on step contact time, which already has taken into account the normal distribution.

\section{Development of a Continuous Probabilistic Walking Load Model}

A continuous walking force time history can be synthesised on the basis of individual footfall forces, with duration depending on the number of steps (i.e., left and right footfalls) and its characteristics based on the statistical distributions of main control points described previously. The continuous walking algorithm illustrated in Figure 12 shows the complete process of creating a synthetic walking force. For a specified walking speed and number of steps (i.e., walking duration), the algorithm first estimates step contact time, first peak load, second peak load, and valley load for a specific person, taking into account intersubject variability. Following that for all number of walking steps, the load and time component intrasubject variabilities are selected via corresponding distribution functions, as mentioned earlier. These result in the main control points for both right and left footfalls. Next, the intermediate points for left and right footfalls can be produced based on the time and load components from the aforementioned control points, such that, for each footfall and each component (i.e., time or load), the intermediate points are obtained, where each step has its intravariabilities. At this step, the algorithm splits into two parallel actions, right footfall and left footfall.

The overlap time is selected as a function of both walking speed and step contact time to combine any consecutive footfalls. The next step integrates everything generated so far to produce the synthetic dynamic load, which is bodyweight-normalised. Pedestrian body mass (body weight), as a random parameter, can be generated via available databases of statistical models in the literature. Finally, a continuous synthetic walking force time history is generated after it has been scaled by the body weight.

Figure 13 shows examples of generated walking time histories at different pacing rates. A total of 64 successive footfalls at sampling frequency of $200 \mathrm{~Hz}$ were generated in the synthetic model, where the first 20 seconds are shown in Figure 13 for clarity. A visual comparison of the signals shows clear variations in walking steps and force amplitudes, as a result of the inherent inter- and intrasubject variability built into the algorithm.

\section{Model Validation}

The modelling strategy proposed in this work is validated in the frequency domain at different pacing frequencies. This was done by comparing between measured Fourier amplitude spectra of pedestrian force time histories at corresponding pacing rates and their synthetic counterparts. As mentioned, 64 successive footfalls were generated the same as the measurement data for 


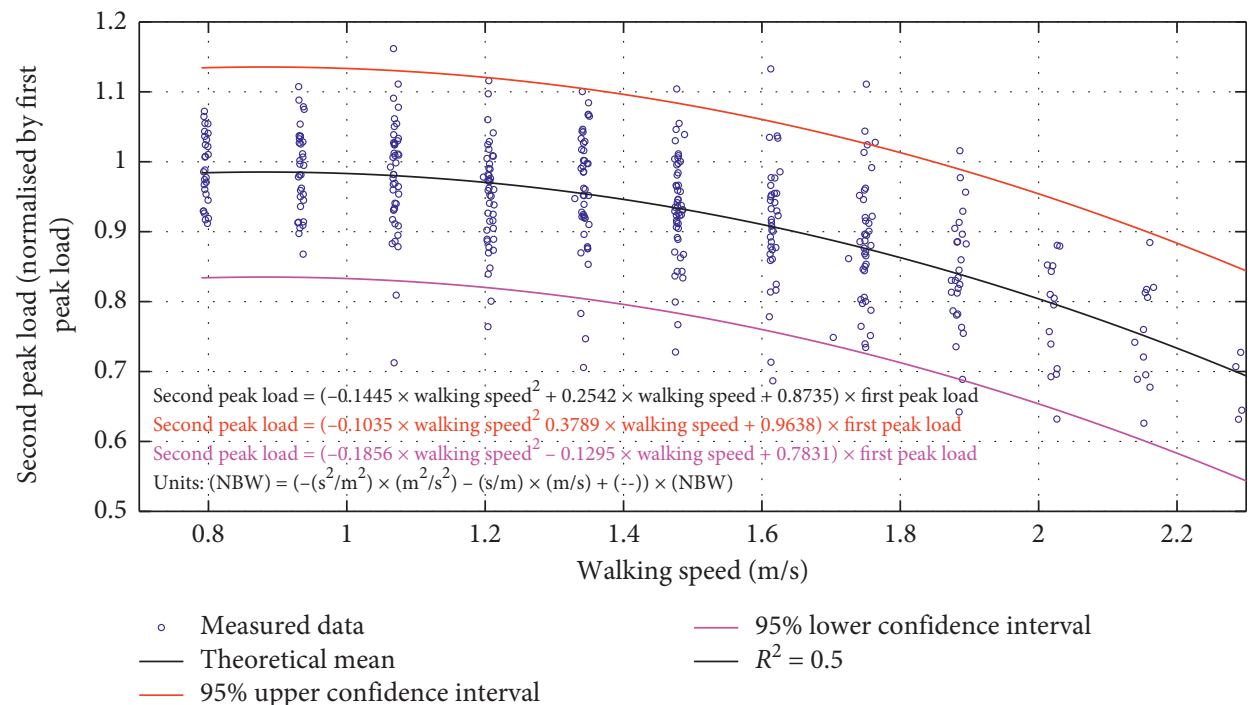

(a)

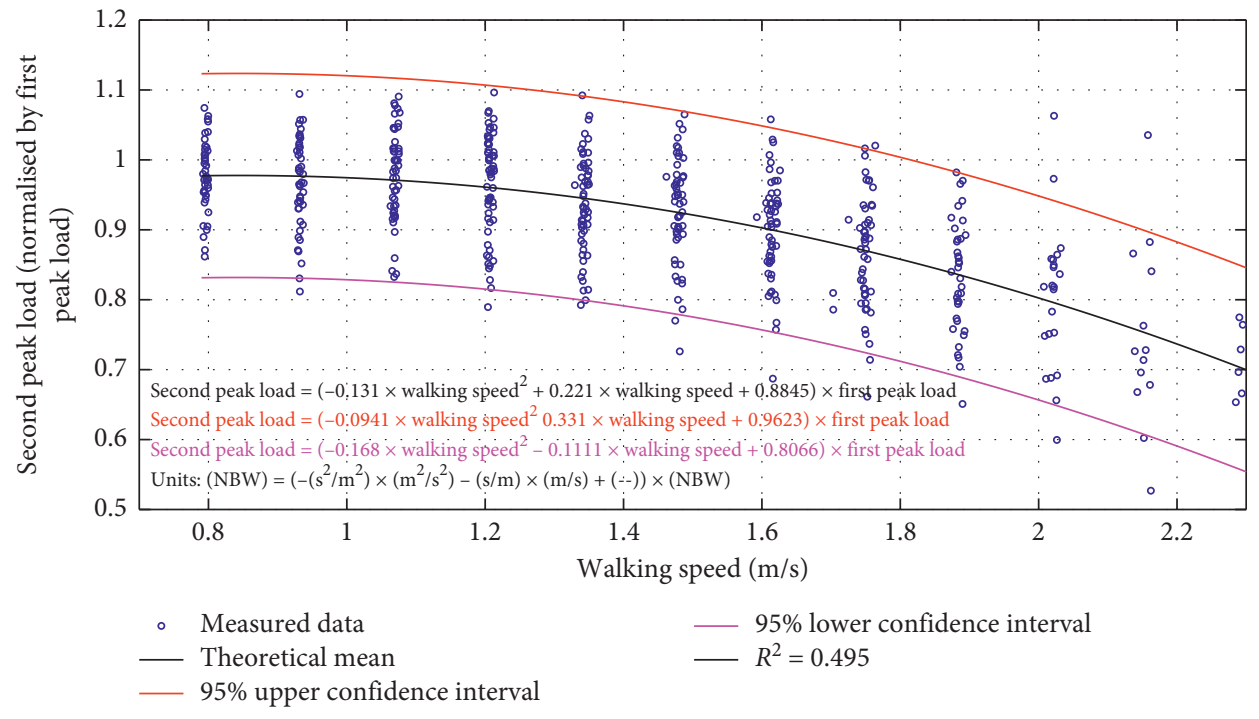

(b)

FIgURE 9: Statistical relationship between walking speed and second peak load. (a) Right footfall; (b) left footfall.

TABLE 1: Intermediate points between the five control points.

\begin{tabular}{lcccc}
\hline Points & Comp. & Left footfall & Right footfall & $R^{2}$ \\
\hline \multirow{2}{*}{ P2 } & Time (s) & $0.134 \times \mathrm{P} 14$ & $0.1374 \times \mathrm{P} 14$ \\
& Load (NBW) & $0.3496 \times \mathrm{P} 3-0.01745$ & $0.4914 \times \mathrm{P} 3-0.01233$ \\
P3 & Time (s) & $0.1964 \times \mathrm{P} 14$ & $0.1976 \times \mathrm{P} 14$ & 0.51 \\
& Load (NBW) & $0.8065 \times \mathrm{P} 6-0.02741$ & $0.7426 \times \mathrm{P} 6-0.00763$ \\
P4 & Time (s) & $0.203 \times \mathrm{P} 14$ & $0.203 \times \mathrm{P} 14$ & 0.81 \\
& Load (NBW) & $0.8518 \times \mathrm{P} 6-0.02441$ & $0.7774 \times \mathrm{P} 6-0.00468$ \\
P5 & Time (s) & $0.214 \times \mathrm{P} 14$ & $0.2147 \times \mathrm{P} 14$ & 0.86 \\
& Load (NBW) & $0.8976 \times \mathrm{P} 6-0.0191$ & $0.8443 \times \mathrm{P} 6-0.0029$ \\
P6 & Time (s) & $0.2413 \times \mathrm{P} 14$ & $0.2395 \times \mathrm{P} 14$ & 0.99 \\
& Load (NBW) & $0.6809 \times \mathrm{P} 7-0.002679$ & $0.5926 \times \mathrm{P} 7+0.02623$ \\
P7 & Time (s) & $0.3039 \times \mathrm{P} 14$ & $0.3055 \times \mathrm{P} 14$ \\
& Load (NBW) & $0.6579 \times \mathrm{P} 9-0.03286$ & $0.9622 \times \mathrm{P} 9-0.04168$ \\
P8 & Time (s) & $0.3567 \times \mathrm{P} 14$ & $0.3564 \times \mathrm{P} 14$ \\
& Load (NBW) & $0.8612 \times \mathrm{P} 9-0.0705$ & 0.65 \\
\end{tabular}


TABle 1: Continued.

\begin{tabular}{|c|c|c|c|c|}
\hline Points & Comp. & Left footfall & Right footfall & $R^{2}$ \\
\hline \multirow{2}{*}{ P9 } & Time (s) & $0.4549 \times \mathrm{P} 14$ & $0.4542 \times \mathrm{P} 14$ & 0.99 \\
\hline & Load (NBW) & $1.017 \times \mathrm{P} 10-0.176$ & $0.9739 \times \mathrm{P} 10-0.1276$ & 0.78 \\
\hline \multirow{2}{*}{ P10 } & Time (s) & $0.5887 \times \mathrm{P} 14-0.00894$ & $0.5892 \times \mathrm{P} 14-0.0092585$ & 0.99 \\
\hline & Load (NBW) & $0.861 \times \mathrm{P} 14-0.126$ & $0.8451 \times \mathrm{P} 14-0.1059$ & 0.63 \\
\hline \multirow{2}{*}{ P11 } & Time (s) & $0.6469 \times \mathrm{P} 14$ & $0.6464 \times \mathrm{P} 14$ & 0.99 \\
\hline & Load (NBW) & $0.8339 \times \mathrm{P} 14-0.03597$ & $0.826 \times \mathrm{P} 14-0.0275$ & 0.73 \\
\hline \multirow{2}{*}{ P12 } & Time (s) & $0.7145 \times \mathrm{P} 14$ & $0.7139 \times \mathrm{P} 14$ & 0.99 \\
\hline & Load (NBW) & $0.8368 \times \mathrm{P} 14+0.02732$ & $0.8392 \times \mathrm{P} 14+0.02514$ & 0.84 \\
\hline \multirow{2}{*}{ P13 } & Time (s) & $0.8331 \times \mathrm{P} 14$ & $0.8331 \times \mathrm{P} 14$ & 0.99 \\
\hline & Load (NBW) & $0.8991 \times \mathrm{P} 14+0.0529$ & $0.8935 \times \mathrm{P} 14+0.05292$ & 0.95 \\
\hline \multirow{2}{*}{ P14 } & Time (s) & First peak time & First peak time & \\
\hline & Load (NBW) & First peak load & First peak load & \\
\hline \multirow{2}{*}{ P15 } & Time (s) & $(0.8111 \times(\mathrm{P} 20-\mathrm{P} 14)+0.0093)-\mathrm{P} 20$ & $(0.8178 \times(\mathrm{P} 20-\mathrm{P} 14)+0.00822)-\mathrm{P} 20$ & 0.96 \\
\hline & Load (NBW) & $(0.9436 \times(\mathrm{P} 14-\mathrm{P} 20)-0.00708)+\mathrm{P} 20$ & $(0.9398 \times(\mathrm{P} 14-\mathrm{P} 20)-0.00606)+\mathrm{P} 20$ & 0.99 \\
\hline \multirow{2}{*}{ P16 } & Time (s) & $(0.6888 \times(\mathrm{P} 20-\mathrm{P} 14)+0.00805)-\mathrm{P} 20$ & $(0.6861 \times(\mathrm{P} 20-\mathrm{P} 14)+0.00857)-\mathrm{P} 20$ & 0.96 \\
\hline & Load (NBW) & $(0.8273 \times(\mathrm{P} 14-\mathrm{P} 20)-0.01898)+\mathrm{P} 20$ & $(0.8249 \times(\mathrm{P} 14-\mathrm{P} 20)-0.0216)+\mathrm{P} 20$ & 0.98 \\
\hline \multirow{2}{*}{$\mathrm{P} 17$} & Time (s) & $(0.5516 \times(\mathrm{P} 20-\mathrm{P} 14)+0.00057)-\mathrm{P} 20$ & $(0.5498 \times(\mathrm{P} 20-\mathrm{P} 14)+0.00608)-\mathrm{P} 20$ & 0.95 \\
\hline & Load (NBW) & $(0.6103 \times(\mathrm{P} 14-\mathrm{P} 20)-0.02642)+\mathrm{P} 20$ & $(0.6074 \times(\mathrm{P} 14-\mathrm{P} 20)-0.02972)+\mathrm{P} 20$ & 0.95 \\
\hline \multirow{2}{*}{ P18 } & Time (s) & $(0.4255 \times(\mathrm{P} 20-\mathrm{P} 14)+0.00465)-\mathrm{P} 20$ & $(0.4902 \times(\mathrm{P} 20-\mathrm{P} 14)+0.00553)-\mathrm{P} 20$ & 0.94 \\
\hline & Load (NBW) & $(0.4005 \times(\mathrm{P} 14-\mathrm{P} 20)-0.02347)+\mathrm{P} 20$ & $(0.4843 \times(\mathrm{P} 14-\mathrm{P} 20)-0.0262)+\mathrm{P} 20$ & 0.92 \\
\hline \multirow{2}{*}{ P19 } & Time (s) & $(0.3161 \times(\mathrm{P} 20-\mathrm{P} 14)+0.00273)-\mathrm{P} 20$ & $(0.3119 \times(\mathrm{P} 20-\mathrm{P} 14)+0.00347)-\mathrm{P} 20$ & 0.94 \\
\hline & Load (NBW) & $(0.4005 \times(\mathrm{P} 14-\mathrm{P} 20)-0.02347)+\mathrm{P} 20$ & $(0.4843 \times(\mathrm{P} 14-\mathrm{P} 20)-0.0262)+\mathrm{P} 20$ & 0.87 \\
\hline \multirow{2}{*}{$\mathrm{P} 20$} & Time (s) & Valley time & Valley time & \\
\hline & Load (NBW) & Valley load & Valley load & \\
\hline \multirow{2}{*}{$\mathrm{P} 21$} & Time (s) & $\mathrm{P} 25-(1.026 \times(\mathrm{P} 25-\mathrm{P} 20)-0.03)$ & $\mathrm{P} 25-(1.015 \times(\mathrm{P} 25-\mathrm{P} 20)-0.0282)$ & 0.99 \\
\hline & Load (NBW) & $(0.0631 \times(\mathrm{P} 25-\mathrm{P} 20)-0.00098)+\mathrm{P} 20$ & $(0.0631 \times(\mathrm{P} 25-\mathrm{P} 20)-0.00128)+\mathrm{P} 20$ & 0.55 \\
\hline \multirow{2}{*}{$\mathrm{P} 22$} & Time (s) & $\mathrm{P} 25-(1.05 \times(\mathrm{P} 25-\mathrm{P} 20)-0.0602)$ & $\mathrm{P} 25-(1.027 \times(\mathrm{P} 25-\mathrm{P} 20)-0.05638)$ & 0.96 \\
\hline & Load (NBW) & $(0.2488 \times(\mathrm{P} 25-\mathrm{P} 20)-0.01212)+\mathrm{P} 20$ & $(0.2485 \times(\mathrm{P} 25-\mathrm{P} 20)-0.01766)+\mathrm{P} 20$ & 0.67 \\
\hline \multirow{2}{*}{$\mathrm{P} 23$} & Time (s) & $\mathrm{P} 25-(1.067 \times(\mathrm{P} 25-\mathrm{P} 20)-0.0886)$ & $\mathrm{P} 25-(1.042 \times(\mathrm{P} 25-\mathrm{P} 20)-0.0843)$ & 0.93 \\
\hline & Load (NBW) & $(0.5145 \times(\mathrm{P} 25-\mathrm{P} 20)-0.03621)+\mathrm{P} 20$ & $(0.5223 \times(\mathrm{P} 25-\mathrm{P} 20)-0.04667)+\mathrm{P} 20$ & 0.77 \\
\hline \multirow{2}{*}{$\mathrm{P} 24$} & Time (s) & $\mathrm{P} 25-(1.055 \times(\mathrm{P} 25-\mathrm{P} 20)-0.119)$ & $\mathrm{P} 25-(1.034 \times(\mathrm{P} 25-\mathrm{P} 20)-0.1159)$ & 0.87 \\
\hline & Load (NBW) & $(0.8567 \times(\mathrm{P} 25-\mathrm{P} 20)-0.06745)+\mathrm{P} 20$ & $(0.869 \times(\mathrm{P} 25-\mathrm{P} 20)-0.07883)+\mathrm{P} 20$ & 0.88 \\
\hline \multirow{2}{*}{ P25 } & Time (s) & Second peak time & Second peak time & \\
\hline & Load (NBW) & Second peak load & Second peak load & \\
\hline \multirow{2}{*}{ P26 } & Time (s) & $1.071 \times \mathrm{P} 25-0.00321$ & $1.088 \times \mathrm{P} 25-0.01337$ & 0.95 \\
\hline & Load (NBW) & $0.847 \times \mathrm{P} 25+0.1096$ & $0.8612 \times \mathrm{P} 25+0.09151$ & 0.88 \\
\hline \multirow{2}{*}{ P27 } & Time (s) & $1.104 \times \mathrm{P} 25-0.00545$ & $1.128 \times \mathrm{P} 25-0.01955$ & 0.97 \\
\hline & Load (NBW) & $0.6564 \times \mathrm{P} 25+0.2541$ & $0.7104 \times \mathrm{P} 25+0.1869$ & 0.63 \\
\hline \multirow{2}{*}{ P28 } & Time (s) & $1.138 \times \mathrm{P} 25-0.00654$ & $1.171 \times \mathrm{P} 25-0.02611$ & 0.96 \\
\hline & Load (NBW) & $0.9204 \times \mathrm{P} 27-0.0917$ & $0.9204 \times \mathrm{P} 27-0.0348$ & 0.63 \\
\hline & Time (s) & $1.159 \times \mathrm{P} 25-0.00755$ & $1.195 \times \mathrm{P} 25-0.02911$ & 0.96 \\
\hline P29 & Load (NBW) & $1.073 \times \mathrm{P} 28-0.1533$ & $1.073 \times \mathrm{P} 28-0.1561$ & 0.89 \\
\hline & Time (s) & $1.182 \times \mathrm{P} 25-0.009348$ & $1.219 \times \mathrm{P} 25-0.03154$ & 0.95 \\
\hline P30 & Load (NBW) & $1.138 \times \mathrm{P} 28-0.3101$ & $1.092 \times \mathrm{P} 28-0.2793$ & 0.77 \\
\hline & Time (s) & $1.207 \times \mathrm{P} 25-0.01035$ & $1.248 \times \mathrm{P} 25-0.03463$ & 0.93 \\
\hline P31 & Load (NBW) & $1.092 \times \mathrm{P} 30-0.2017$ & $1.017 \times \mathrm{P} 30-0.1811$ & 0.93 \\
\hline & Time (s) & $1.245 \times \mathrm{P} 25-0.01227$ & $1.289 \times \mathrm{P} 25-0.03903$ & 0.94 \\
\hline P32 & Load (NBW) & $0.9973 \times \mathrm{P} 30-0.321$ & $0.841 \times \mathrm{P} 30-0.2263$ & 0.85 \\
\hline & Time (s) & $1.345 \times \mathrm{P} 25-0.01648$ & $1.399 \times \mathrm{P} 25-0.0495$ & 0.88 \\
\hline P33 & Load (NBW) & $\mu=0.0634 s=0.029$ & $\mu=0.0617 s=0.0237$ & \\
\hline & Time (s) & Step contact time & Step contact time & \\
\hline P34 & Load (NBW) & 0 & 0 & \\
\hline
\end{tabular}

comparison. Figure 13 shows typical time domain signals of three pacing rates of synthetic walking to be used for validation.

Figures 14-16 illustrate Fourier spectra of measured and synthetic time histories corresponding with three pacing rates $\left(f_{p}\right)$ of $1.8,2.0$, and $2.2 \mathrm{~Hz}$, representing typical likely pacing rates for office floors. For the first four dominant harmonics, square root of sum of squares (SRSS) error in the area under the graph between the measured and synthetic spectra over 10 different walking forces for each pacing rate is less than $12 \%$. In addition, the measurement of spread of energy around the first four dominant harmonics (i.e., $H$ 


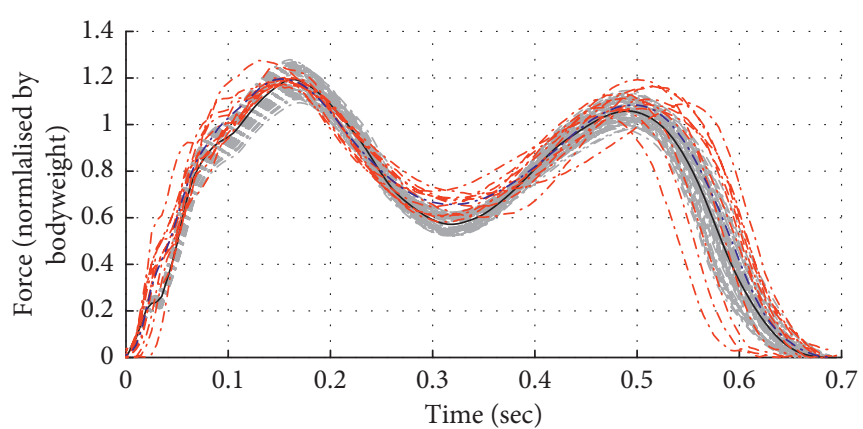

Synthetic steps $\quad$-.-- Measured steps

Mean synthetic steps $\quad$...- Mean measured steps

(a)

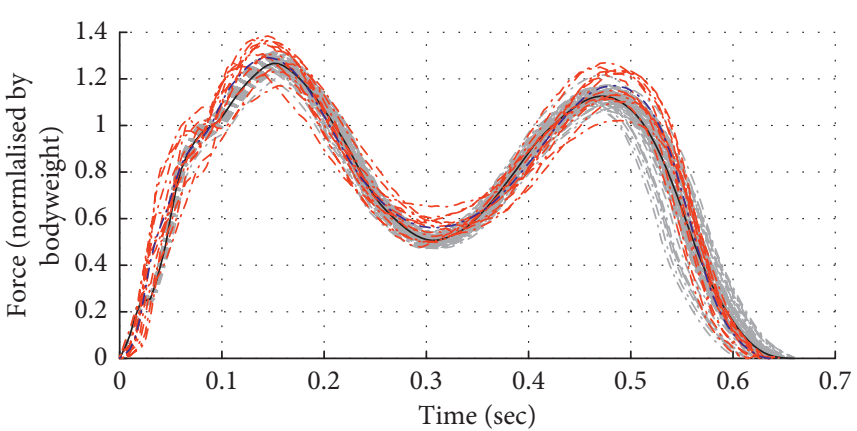

-..- Synthetic steps $\quad$-..- Measured steps

_ Mean synthetic steps $\quad$. ..-. Mean measured steps

(b)

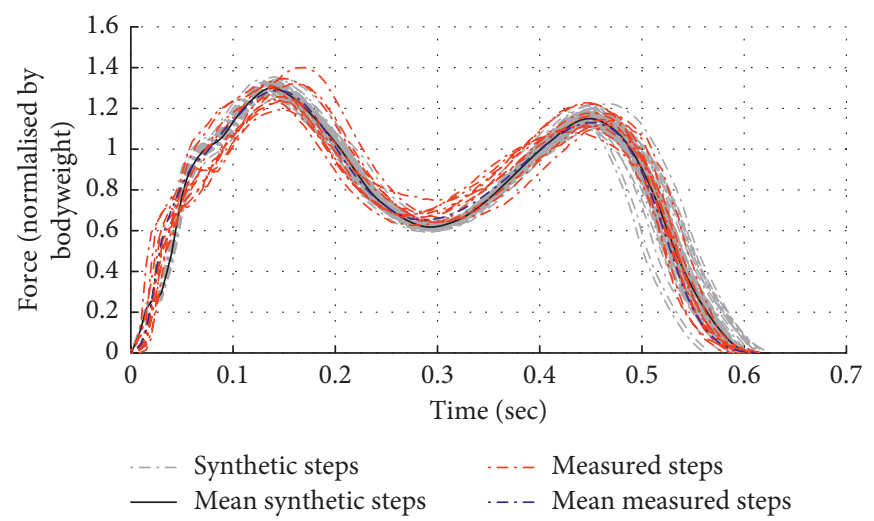

(c)

Figure 10: Comparison of synthetic walking steps against measured steps. (a) Pacing rate of $1.8 \mathrm{~Hz}$, (b) pacing rate of $2.0 \mathrm{~Hz}$, and (c) pacing rate of $2.2 \mathrm{~Hz}$.

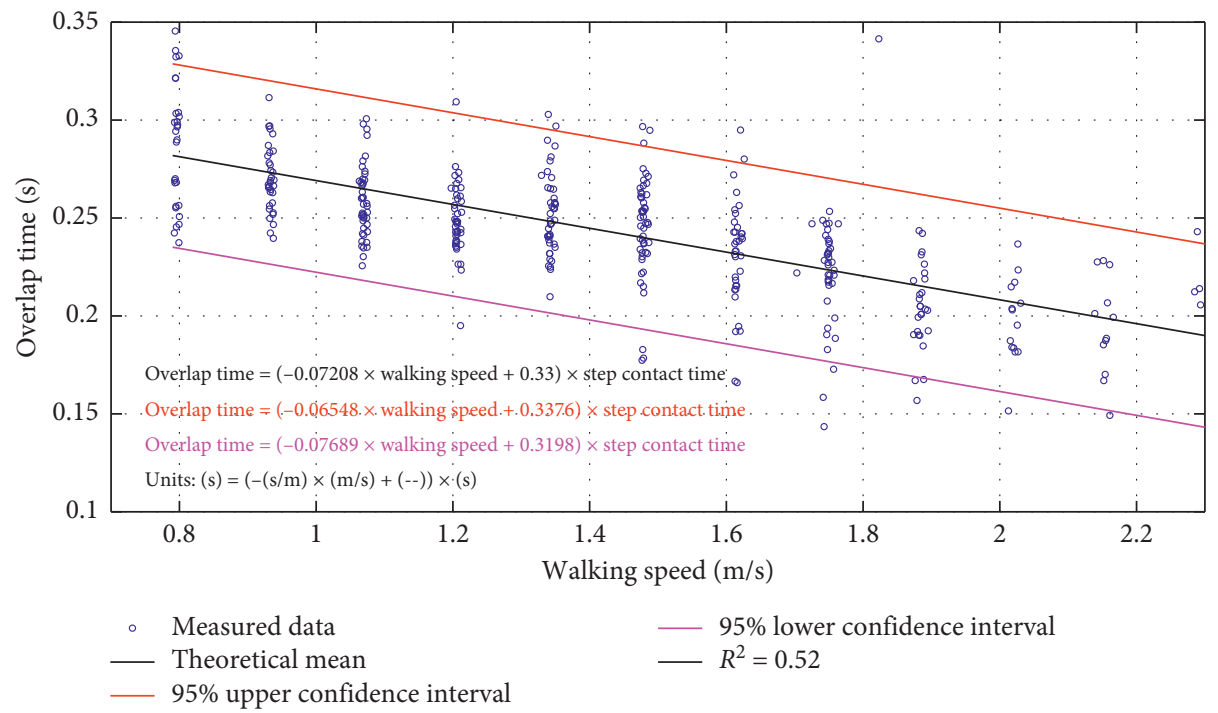

Figure 11: Overlap time relationship.

harmonic number) in the aforementioned spectra was computed using area under each harmonic curve to represent the spread of energy. The values of upper frequency and lower frequency were identified as $0.95 \mathrm{Hf}_{p}$ and $1.05 H f_{p}$, respectively, based on [12].
The results illustrated in Table 2 demonstrate the extent of spread of energy around main harmonics in terms of mean and standard deviations. Overall, the synthetic model is in agreement with measured spectra, despite some errors which are acceptable in the context of human 


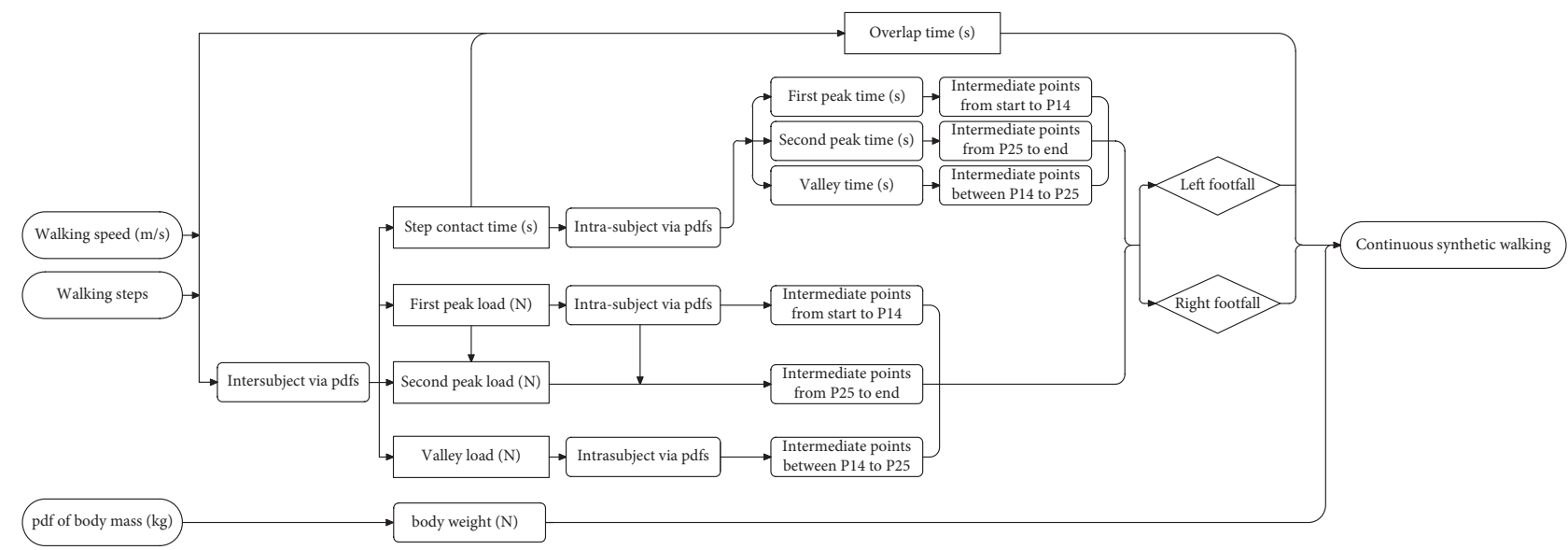

FIGURE 12: Schematic flow chart describing the procedure for generating synthetic continuous walking.
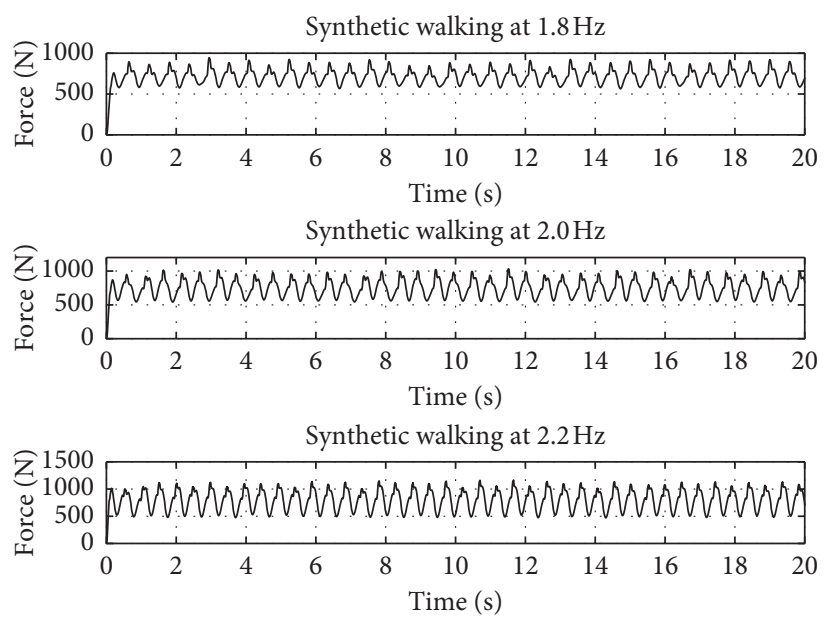

FIGURE 13: Synthetic continuous walking at three pacing frequencies.
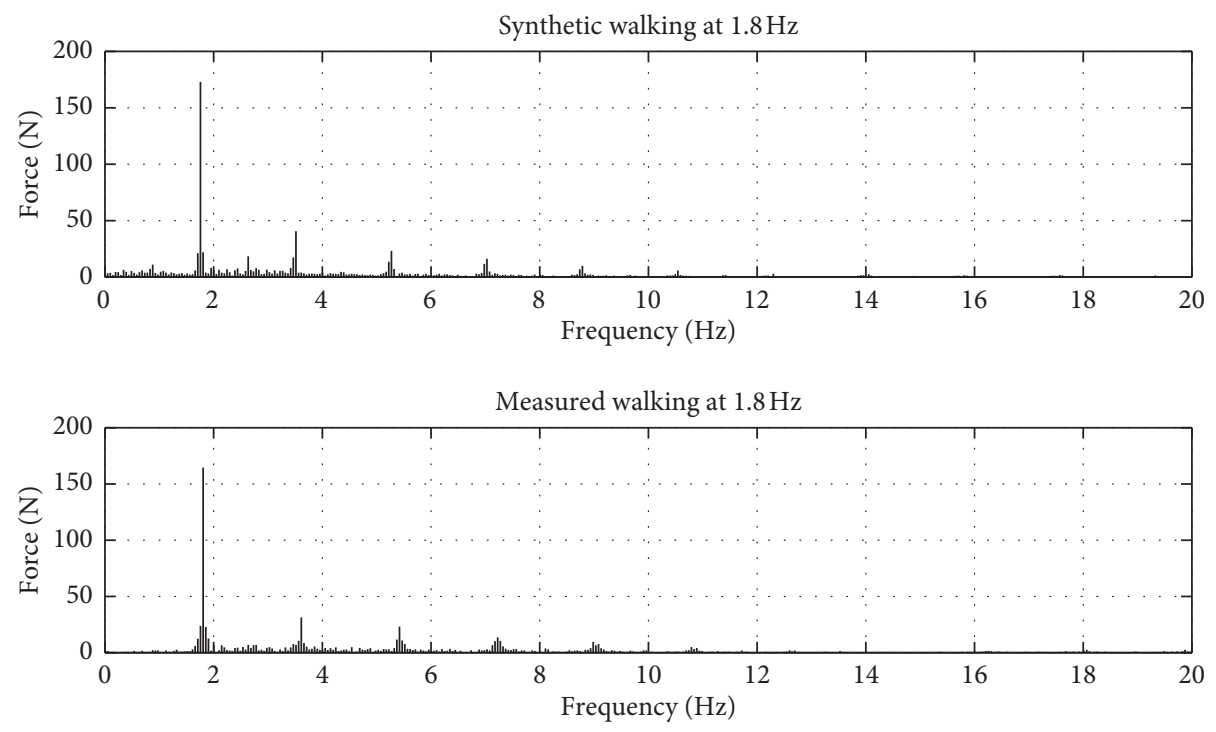

FIGURE 14: Synthetic continuous walking and measured walking at $1.8 \mathrm{~Hz}$. 

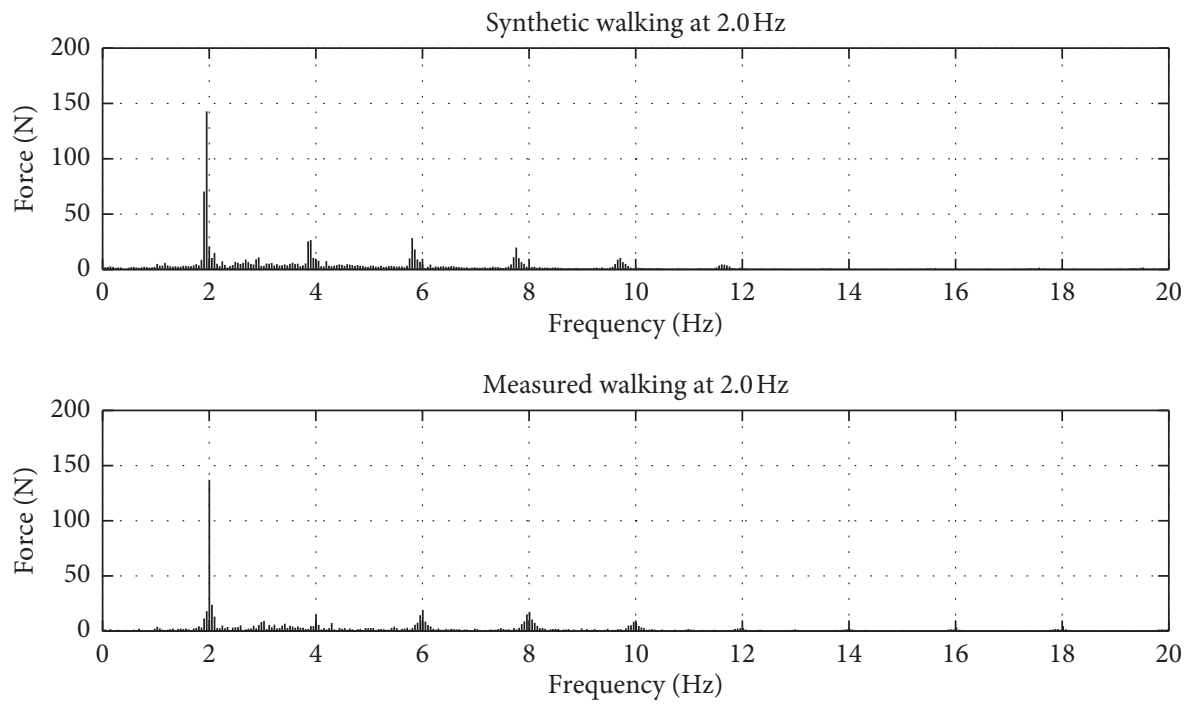

FIGURE 15: Synthetic continuous walking and measured walking at $2.0 \mathrm{~Hz}$.
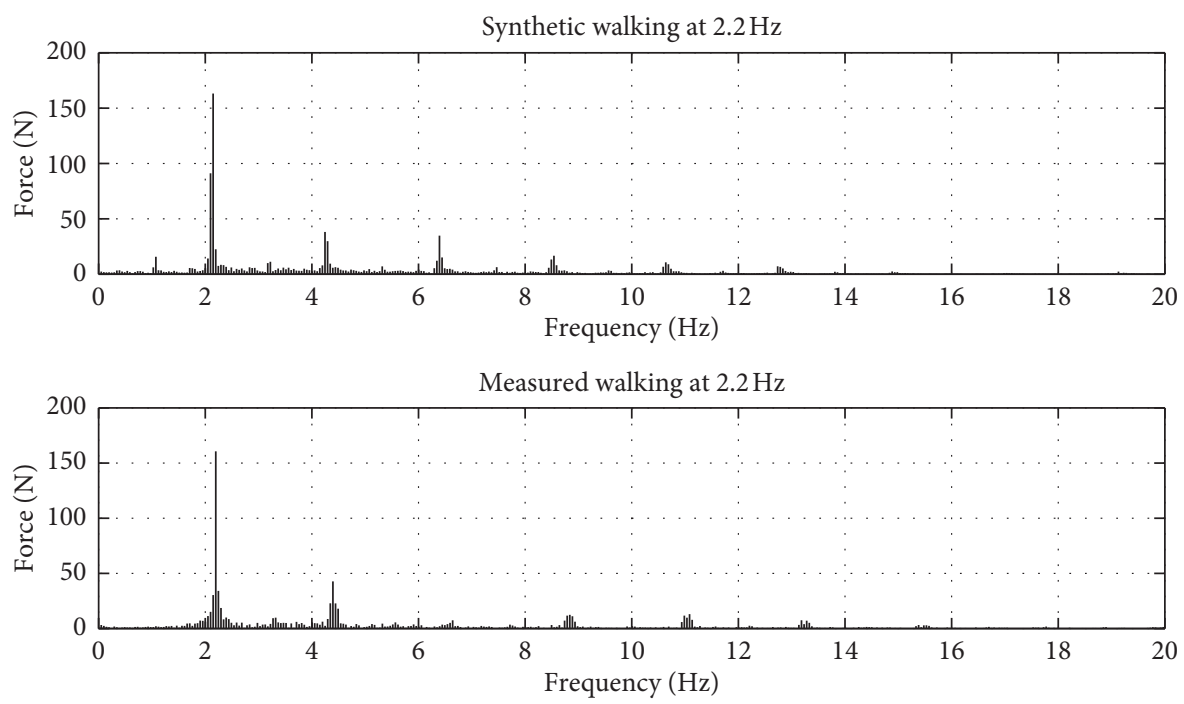

FIGURE 16: Synthetic continuous walking and measured walking at $2.2 \mathrm{~Hz}$.

TABLE 2: Spread of energy in the spectra for the synthetic and measured walking.

\begin{tabular}{lccc}
\hline Harmonic number & Area synthetic walking & Area measured walking & $\%$ error \\
\hline 1 & $\mu=0.0138 ; \sigma=0.0034$ & $\mu=0.014 ; \sigma=0.003$ & -1.43 \\
2 & $\mu=0.0046 ; \sigma=0.0012$ & $\mu=0.0047 ; \sigma=0.0027$ & -2.12 \\
3 & $\mu=0.0039 ; \sigma=0.0009$ & $\mu=0.0032 ; \sigma=0.001$ & 17.9 \\
4 & $\mu=0.0032 ; \sigma=0.0006$ & $\mu=0.0034 ; \sigma=0.0004$ & -6.2 \\
\hline
\end{tabular}

forcing function and mathematical modelling. All this indicates good match in the frequency content between the measured and synthesised walking force signals. Therefore, it is proposed that the synthetic forces generated by this model can be utilised as a basis for vibration serviceability assessment of civil engineering structures, such as floors and footbridges, to estimate more realistic vibration responses due to people walking than previously proposed deterministic models.

\section{Conclusions}

This paper has presented a new probabilistic model to generate walking force time histories for specific walking speeds. The footfall forces of both left and right legs are modelled separately and then combined with an overlap time to obtain a continuous walking force. The modelling strategy can account for spatial-temporal features of real vertical walking more realistically than conventional Fourier series-based deterministic 
approaches. The established probabilistic model has the following advantages:

(1) A set of probabilistic walking steps, taking into account intrasubject variability, is used to generate a continuous walking force signal in the time domain based on walking speed

(2) High-frequency components are inherently included due to variation in walking steps in both time and load. Hence, the load model can replicate actual walking more realistically than Fourier series approaches typically based on low-frequency harmonics alone

(3) Variation between walking steps for both legs in each interval of consecutive steps is possible and as such the model demonstrates the narrow band random phenomenon in frequency domain, showing the leaking of energy in the vicinity of the dominant Fourier harmonics [11]. This is a feature typical in measured pedestrian time histories

(4) Intersubject variability is taken into account via the statistical distributions of physical characteristics of entire populations of pedestrians

(5) The walking model can be used to generate force time histories for both individual and multiple pedestrians walking via superposition

(6) It is worth mentioning that this model does not account for human-structure interaction and as such further investigation is required to include that aspect. Also, the model could be improved by explicitly introducing a space variable

(7) The model is amenable for use in Monte-Carlo simulations of floor response, hence to provide statistical distributions of response to be used in probabilistic vibration serviceability assessment. It can also be used to predict likely "vibration dose" over an extended time period of occupant exposure to vibration

This framework of probabilistic walking forces provides an opportunity to enhance current vibration serviceability assessment, which currently typically lacks appropriate statistical perspective. The established walking model can be used to predict realistic distributions of dynamic structural responses for assessment of civil engineering structures dynamically excited by pedestrians such as building floors and footbridges.

\section{Data Availability}

The experimental database is confidential and thus cannot be provided.

\section{Conflicts of Interest}

The authors declare that they have no conflicts of interest.

\section{Acknowledgments}

The financial support for this research was prdovided by Qatar National Research Fund (QNRF; a member of the
Qatar Foundation) via the National Priorities Research Program (NPRP) (Project no. NPRP8-836-2-353). The authors would like to acknowledge Professor James Brownjohn and Professor Vitomir Racic for providing access to the database of measured walking forces.

\section{References}

[1] T. M. Murray, D. E. Allen, E. E. Ungar, and D. B. Davis, Vibrations of Steel-Framed Structural Systems Due to Human Activity, American Institute of Steel Construction (AISC), Chicago, IL, USA, 2016.

[2] A. Smith, S. Hicks, and P. Devine, Design of Floors for Vibration: A New Approach, Steel Construction Institute (SCI), Berkshire, UK, 2nd edition, 2009.

[3] M. Willford and P. Young, A Design Guide for Footfall Induced Vibration of Structures, Concrete Centre (CC), Surry, UK, 2006.

[4] RFCS, Human Induced Vibrations of Steel Structures (HiVoSS) -Vibration Design of Floors: Background Documnet, European Comission-RFCS, Brussels, Belgium, 2007.

[5] J. Brownjohn, V. Racic, and J. Chen, "Universal response spectrum procedure for predicting walking-induced floor vibration," Mechanical Systems and Signal Processing, vol. 7071, no. 1, pp. 741-755, 2016.

[6] Z. O. Muhammad and P. Reynolds, "Vibration serviceability of building floors: performance evaluation of contemporary design guidelines," Journal of Performance of Constructed Facilities, vol. 33, no. 2, Article ID 01019012, 2019.

[7] Z. Muhammad, P. Reynolds, O. Avci, and M. Hussein, "Review of pedestrian load models for vibration serviceability assessment of floor structures," Vibration, vol. 2, no. 1, pp. 1-24, 2018.

[8] A. F. Al-Anbaki, Footfall excitation of higher modes of vibration in low-frequency building floors, Ph.D. thesis, The University of Exeter, Exeter, UK, 2018.

[9] M. Bocian, J. H. G. Macdonald, J. F. Burn, and D. Redmill, "Experimental identification of the behaviour of and lateral forces from freely-walking pedestrians on laterally oscillating structures in a virtual reality environment," Engineering Structures, vol. 105, no. 12, pp. 62-76, 2015.

[10] S. Zivanović and A. Pavic, "Probabilistic modeling of walking excitation for building floors," Journal of Performance of Constructed Facilities, vol. 23, no. 3, pp. 132-143, 2009.

[11] V. Racic and J. M. W. Brownjohn, "Stochastic model of nearperiodic vertical loads due to humans walking," Advanced Engineering Informatics, vol. 25, no. 2, pp. 259-275, 2011.

[12] S. Zivanović, Probability-based estimation of vibration for pedestrian structures due to walking, Ph.D. thesis, The University of Sheffield, Sheffield, UK, 2006.

[13] S. C. Kerr, Human induced loading on staircases, Ph.D. thesis, University College London, London, UK, 1998.

[14] J. M. W. Brownjohn, A. Pavic, and P. Omenzetter, "A spectral density approach for modelling continuous vertical forces on pedestrian structures due to walking," Canadian Journal of Civil Engineering, vol. 31, no. 1, pp. 65-77, 2004.

[15] R. W. Bohannon, "Comfortable and maximum walking speed of adults aged 20-79 years: reference values and determinants," Age and Ageing, vol. 26, no. 1, pp. 15-19, 1997.

[16] H. V. Dang and S. Živanović, "Experimental characterisation of walking locomotion on rigid level surfaces using motion capture system," Engineering Structures, vol. 91, no. 3, pp. 141-154, 2015. 
[17] A. J. J. Smith and E. D. Lemaire, "Temporal-spatial gait parameter models of very slow walking," Gait \& Posture, vol. 61, no. 3, pp. 125-129, 2018.

[18] N. R. Draper and H. Smith, Applied Regression Analysis, John Wiley \& Sons, Inc., Hoboken, NJ, USA, 3rd edition, 1998. 


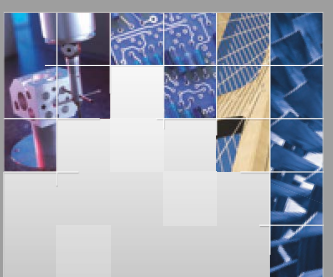

\section{Enfincering}
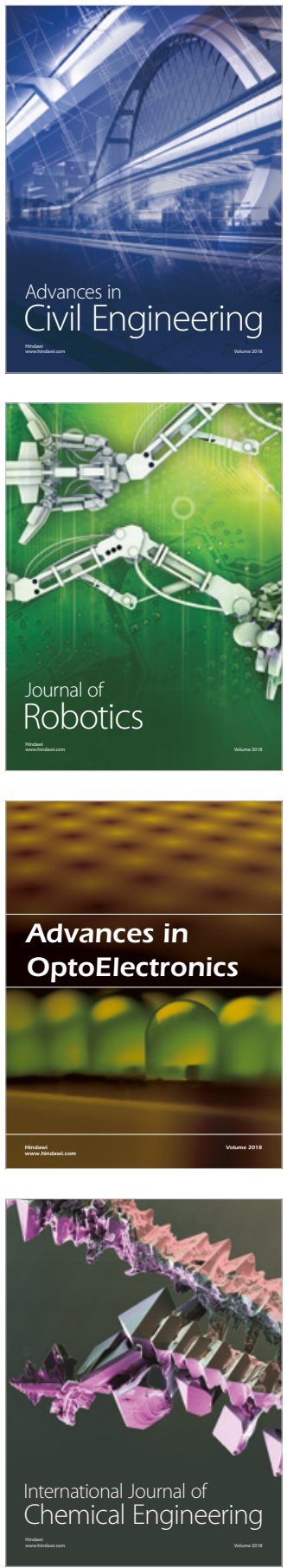

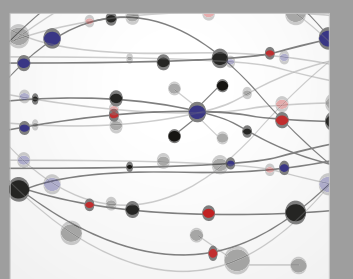

\section{Rotating \\ Machinery}

The Scientific World Journal

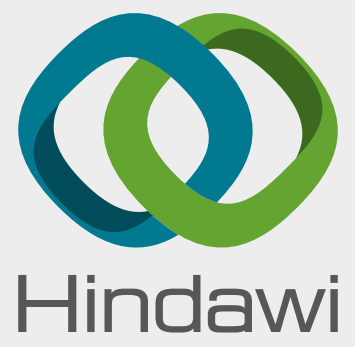

Submit your manuscripts at

www.hindawi.com
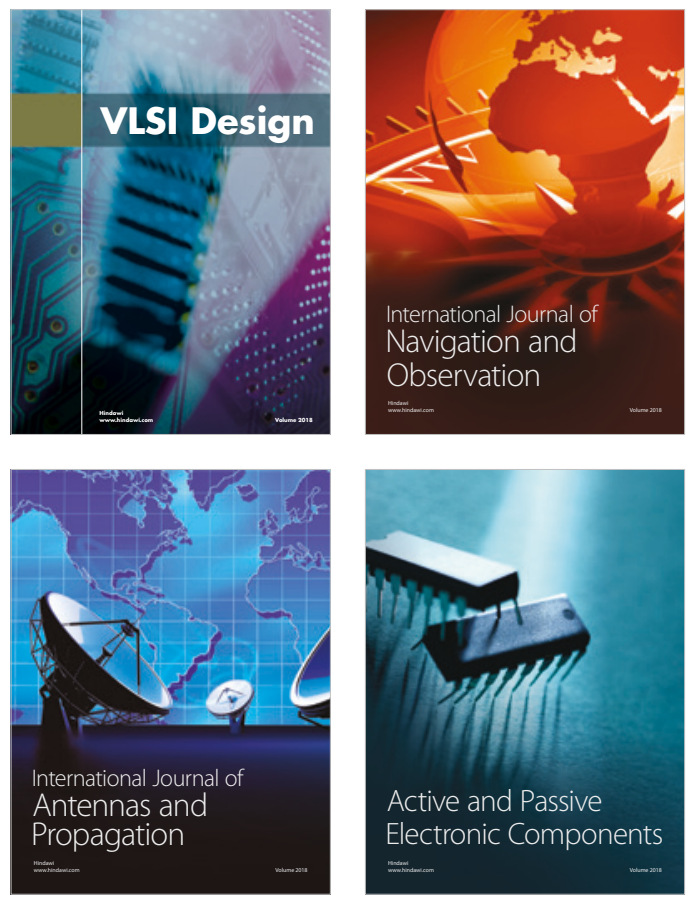
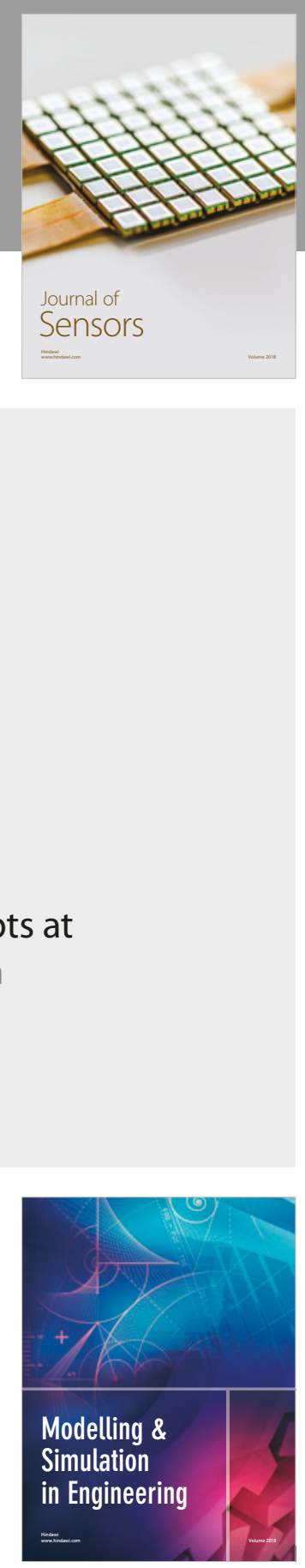

\section{Advances \\ Multimedia}
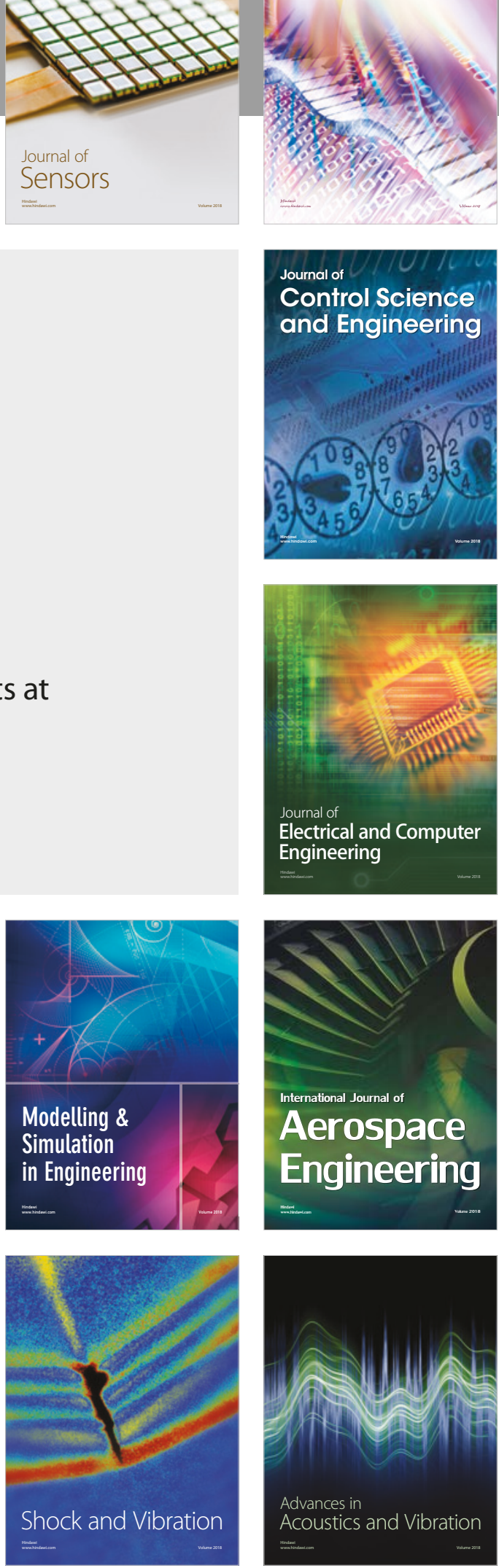